\title{
Age stratified, matched comparison of unicompartmental and total knee replacement
}

Authors' names: JA Kennedy ${ }^{\mathrm{a}}$, HR Mohammad ${ }^{\mathrm{a}}$, SJ Mellon ${ }^{\mathrm{a}}$, CAF Dodd ${ }^{\mathrm{b}}$, DW Murray ${ }^{\mathrm{a}, \mathrm{b}}$

Affiliation:

${ }^{a}$ Nuffield Department of Orthopaedics, Rheumatology and Musculoskeletal Sciences, University of Oxford

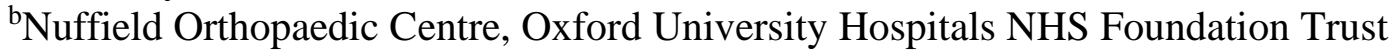

Corresponding author: JA Kennedy; james.kennedy@ndorms.ox.ac.uk

Key words: unicompartmental knee replacement; total knee replacement; comparison; functional outcome; implant revision; age

Funding: This research did not receive any specific grant from funding agencies in the public, commercial, or not-for-profit sectors.

Declaration of interest: The author or one or more of the authors have received or will receive benefits for personal or professional use from a commercial party related directly or indirectly to the subject of this article. The funding source played no role in the design, conduct or interpretation of this study. 


\section{Age stratified, matched comparison of unicompartmental and total knee replacement}

\section{Introduction:}

Knee replacement rates are increasing worldwide, and the most rapid increase in provision is in those younger than 60 years of age[1]. About half of patients undergoing knee replacement are eligible for unicompartmental knee replacement (UKR)[2, 3], and younger patients are more likely to receive UKR than their elderly peers[4]. Worldwide UKR is used for less than $10 \%$ of knee replacements, with the remainder being total knee replacement (TKR)[5-8]. We are not aware of any matched studies comparing patient reported outcomes and revision rates of UKR and TKR in different age groups.

In large age standardised comparisons between UKR and TKR, UKR has been shown to have better patient reported outcomes[2, 9, 10], faster recovery[11, 12] and reduced morbidity and mortality[13-16] at the expense of a higher revision rate[13]. Additionally, in comparing age groups, all national joint registries report increased revision rates in younger patient groupings, with younger patients commonly defined as younger than 55 or 60 years of age at operation[58]. This finding is typically attributed to increased activity levels which places greater stress on the prosthesis and bone prosthesis interface which leads to revision predominantly due to loosening or implant failure.

The aim of our study was to compare the functional outcome and failure rate of medial UKR and TKR in different age groups. To ensure a fair comparison it was a requirement that the UKR were all implanted for the recommended indications and that they were matched to TKR that were also implanted in knees that were appropriate for UKR.

\section{Materials and Methods:}

2.1 Study overview: We identified two large, separate, prospective cohorts followed for a median of ten years with baseline demographics and outcome measures (Figure 1). One was a series of medial UKR implanted for the recommended indications. The other was a series of 
TKR in which intraoperative findings were recorded so we could deduce which should have been appropriate for UKR. We propensity score matched patients with UKR to patients with TKR that could have had UKR. Following matching we analysed the Oxford Knee Score (OKS, a patient reported outcome), revision rates and 'failure', which was defined as a composite of revision or reoperation or no improvement in OKS.

2.2 Cohorts: One cohort was TKR patients from the Knee Arthroplasty Trial (KAT)[17]. KAT is a multicentre randomised controlled trial undertaken in the United Kingdom to prospectively evaluate different aspects of TKR design. 2352 participants were recruited between July 1999 and January 2003. The original study design included an arm for UKR implantation which was abandoned because of poor recruitment; the 18 patients that received UKR were not included in this study. Patients received yearly postal questionnaires with the primary outcome measure being the OKS. Postal and telephone reminders were undertaken to complete data collection. Hospitals were contacted for details of readmissions. For this study, we have not taken into account the randomisation, thus forming a prospective cohort. Knees with inflammatory arthritis, in valgus, or with a deficient anterior cruciate ligament were excluded so that those analysed should have been eligible for medial UKR.

The second cohort was a prospectively followed series of 1000 consecutive phase 3 cemented Oxford medial mobile-bearing UKR (Zimmer Biomet, Warsaw, Indiana) implanted in 818 patients. Two designer surgeons performed all procedures using recommended indications, which are: anteromedial osteoarthritis[18], with medial compartment bone-on-bone arthritis, full thickness cartilage in the lateral compartment, and functionally intact anterior cruciate and medial collateral ligaments; and medial avascular necrosis. Patients were not excluded based on age, weight, sex, activity level, lateral compartment osteophytes, or the presence of patellofemoral cartilage loss. All knees were implanted between June 1998 and March 2009. The patients were assessed clinically at five and ten years and by postal questionnaires, with 
subsequent telephone follow up if required. This cohort has a median ten year follow up and the primary outcome measure was the OKS.

Knees were included providing they were eligible for medial UKR, had required variables for matching, and follow up data with information regarding revision status. Matching was generated within age-strata by logistic regression based on patient age at surgery, patient sex, preoperative weight, preoperative OKS and length of follow up. Nearest neighbour matching without replacement was used, with a calliper of 0.2 standard deviations specified within which controls could be drawn[19]. Standardised mean differences were used to assess the success of matching (a standardised mean difference of $<0.1$ indicating satisfactory matching).

2.3 Outcomes: Mean and median OKS[20] (48 best) are the primary outcome for pain and function. The percentage of patients falling into OKS categories corresponding to excellent (>41 points), good (34 to 41$)$, satisfactory (27 to 33) and poor $(<27)$, the percentage not meeting minimum change associated with the knee being "better" of nine points[21], and those with no improvement, whose final OKS was worse than their pre-op OKS, were also calculated. The percentage of possible change (POPC) in OKS was calculated by dividing the improvement by the total possible improvement[22].

Revision was defined similarly to the National Joint Registry of England, Wales, Northern Ireland and the Isle of Man[5], meaning that any component removal, addition or exchange were considered revisions. In addition we counted amputation and periprosthetic fractures requiring open reduction and internal fixation as revision. Furthermore, a major revision was defined as any further surgery requiring more than a single-stage operation with primary TKR components, such as a revision with stems, wedges or constrained implants. A reoperation included any knee procedure requiring the administration of general or regional anaesthetic including manipulations and washouts. 
Finally, we defined a composite outcome measure representing "failure of the knee replacement", which was defined as patients that had a revision or re-operation, or no improvement in OKS between pre-op and final score.

A sensitivity analysis was undertaken using all available data without matching to assess the impact of excluding patients with missing data.

2.4 Statistical analysis: Significance in OKS was tested between groups with a Student's t tests and Mann-Whitney-U tests. Categorical variables were tested with a Chi-Squared test. Revision rates were determined per 100 component-years, and Kaplan-Meier implant survival estimates calculated. Significance was tested with a log-rank test. $\mathrm{P}<0.05$ was considered statistically significant and $\mathrm{p}<0.01$ highly statistically significant.

2.5 Ethical approval: KAT received ethical approval from the Multicentre Research Ethics Committee for Scotland (ref: MREC/98/0/100). Ethical approval for the follow up of UKR patients was sought but deemed not required under NHS research governance arrangements.

Software: R statistical programming software was utilised. Matching was performed with the MatchIt package.

\section{Results:}

Following removal of knees that were not appropriate for medial UKR or had incomplete data there were 2067 knees that were appropriate for UKR and that had had either TKR or UKR, (Figure 1). There were differences in baseline characteristics between the TKR and UKR in this unmatched dataset with the preoperative OKS being significantly higher in UKR in all age groups (Table 1). Therefore matching is essential, particularly for exploring differences in functional outcome. For survival analysis this is not so critical: In the unmatched patients the 10 year implant survival was not significantly different in the two older age groups (60-75 
years, TKR 96\%, UKR 94\% and 75+, 96\% and 93\%). However in those <60 years survival the ten year survival was significantly different (TKR 86\%, UKR 96\%, p<0.001, Table 2).

Following matching there were 1485 knees (UKR $n=528, T K R n=957)$. There were no differences in baseline covariates and, in particular the pre-operative OKS were well matched in all age groups (Table 1). There was significant improvement in OKS following surgery for TKR and UKR in all age groups. In all age groups the OKS was better in UKR than TKR (Table 3, Figure 2): Reporting youngest group $(<60)$ to eldest $(75+)$; at five years the difference in median OKS was 8, 4, and 4 (all $\mathrm{p}<0.01)$, and at ten years it was 12,5 and 2 ( $\mathrm{p}<0.001$, except $75+, p=0.24)$. In all age groups a higher proportion of TKR had fewer excellent outcome scores than UKR, being respectively from young to old at 5 years: $30 \%$ vs $63 \%, 38 \%$ vs $65 \%$, and 40 vs $54 \%$ ( $\mathrm{p}<0.001$, except $75+, \mathrm{p}=0.04)$; and at 10 years: $21 \%$ vs $63 \%, 33 \%$ vs $52 \%$, and $27 \%$ vs $34 \%$ (p<0.001, except $75+, p=0.46)$.

Ten-year revision-free survival, reporting TKR vs UKR, was $89 \%$ (95\% CI 82-96) vs 93\% (CI 88-98; $\mathrm{p}=0.19$ ) in those younger than 60 years, 95\% (CI 94-97) vs 95\% (CI 92-98; $\mathrm{p}=0.95$ ) in those 60 to 75 years, and 95\% (CI 92-98) vs 90\% (CI 83-98, $\mathrm{p}=0.52$ ) in those 75 years or older at surgery (Tables 4-6, Figure 3). With major revision as the end-point (eg those requiring revision TKR components with stems, wedges and constrained implants), ten-year survival was $91 \%$ vs $100 \%(\mathrm{p}=0.003), 96 \%$ vs $99 \%(\mathrm{p}=0.004)$, and $96 \%$ vs $100 \%(\mathrm{p}=0.05)$ from youngest to eldest group respectively.

For the composite outcome measure of revision/re-operation or no improvement in OKS, the failure rate of TKR and UKR in those $<60$ was $23 \%$ (95\% CI 14-32) and $15 \%$ (CI 8-22; $\mathrm{p}=0.16)$, in those $60-75$ was $17 \%(\mathrm{CI} 14-20)$ and $12 \%(\mathrm{CI} 8-15, \mathrm{p}=0.05)$, in those $>75$ was $19 \%$ (CI 14-24) and 15\% (CI 8-21; $\mathrm{p}=0.29$ ), and in all age groups combined was $18 \%$ (CI 15-20) and $13 \%$ (CI 10-16; p=0.02; Figure 4). 


\section{Discussion:}

Most comparisons of knee replacement are based on revision rate in unmatched cohorts, and can often be misleading. When assessing the relative merits of different types of knee replacement it is essential to match patients and to consider not only the revision rate but also the functional outcome, pain relief, other measures of failure and morbidity and mortality. In this matched study we assessed pain and function with the OKS and found that overall UKR provided significantly better outcome scores than TKR. There was no significant difference in the overall ten year revision rate (TKR 5.1\% UKR 5.5\%, p=0.85). However if the ten year failure is defined in a way more relevant to patients, for example if there is no improvement in symptoms or further surgery is required, then overall UKR had a significantly lower failure rate than TKR (TKR 18\%, UKR 12\%, p=0.02). These and other comparisons are shown in Figure 4. The study was too small to analyse medical complications. However a matched study based on registry data has shown that following UKR the incidence during the first three months of death and major medical complications, such as stroke, myocardial infarction, thrombo-embolism and deep infection is about half that following TKR, and the time in hospital following surgery is shorter $[13,14]$. These studies therefore clearly supports the use of UKR, when appropriate. However the relative merits are different in different age groups (Figure 4).

Most knee replacements are done in patients between the age of 60 and 75[23]. In this age group the priorities of surgery are to provide pain relief and a well-functioning knee that does not require further operations. This study found the ten year OKS was appreciably better (five points, $\mathrm{p}<0.001)$ with UKR than TKR. Furthermore about $30 \%(\mathrm{p}<0.001)$ more UKR patients achieved excellent outcomes and 5\% $(\mathrm{p}=0.005)$ fewer had no improvement in OKS compared to pre-op. The ten year revision rate was not appreciably different (UKR 5.2\% v 4.6\%; $\mathrm{p}=0.95$ ). 
However the major revision rate $(0.6 \% \mathrm{v} 3.1 \%, \mathrm{p}<0.01)$ was significantly lower with UKR. Furthermore the composite failure of worse OKS than pre-operation or further surgery occurred $(5 \%, \mathrm{p}=0.05)$.

In the elderly $(>75)$, the priorities of surgery include restoring appropriate function and alleviating pain, but with greater emphasis on safety owing to a higher prevalence of frailty[24, 25] In this study the OKS was better after UKR, with the difference being 4 points at 5 years ( $p<0.01$ ), decreasing to 2 points at 10 years; presumably because of increasing frailty as their average age would be 90 at that stage. Over the whole study period $6 \%(\mathrm{p}=0.01)$ less UKR patients had no improvement in OKS compared to pre-op. Due to the patient's age and comorbidities the lower death and medical complication rate with UKR shown in registry studies are a real advantage. It is also very important for these elderly patients to avoid further major surgery such as revision and particularly major revision. The patient's life expectancy is similar to the length of our study so the incidence of revision (TKR 5\%, UKR 6\%) and major revision (TKR 3\%, UKR 0\%) in the study will be similar to the risk of these events occurring in the patients remaining life time. Therefore the general view that in the elderly TKR is a better solution than UKR is erroneous.

In young patients the priorities are to have high levels of function, and for the knee replacement to last as long as possible. If the knee requires a revision, it should have as good an outcome as possible and therefore avoiding a major revision with stems, wedges and stabilised implants is an advantage. In younger patients $(<60)$ every outcome favoured UKR. At ten years the OKS was markedly better $(12$ points, $\mathrm{p}<0.001)$ and $37 \%(\mathrm{p}<0.001)$ more patients achieved excellent outcomes. The major revision rate, the revision rate and the reoperation/revision rate were lower $(\mathrm{p}=0.003, \mathrm{p}=0.54, \mathrm{p}=0.25)$. In addition the composite failure of worse OKS than pre-op or revision/reoperation was lower $(\mathrm{p}=0.16)$. 
The most surprising finding was that in young patients the survival of UKR was not worse than TKR. Although it was better, the difference was not significant. However this may have been because the numbers were small as in the non-matched data the revision rate was significantly better. Several factors may contribute to this. Firstly the UKR were done for bone-on-bone arthritis, in whom UKR are known to do well[3, 9, 26-28]. However in young patients UKR is often used for early arthritis, without bone-on-bone and in this situation it is unreliable and has a high revision rate[29, 30]. This likely contributes to the high revision rate seen in registries. Secondly in young active patients TKR tend to be revised because the implant or fixation fail due to higher stresses on the implant. With UKR, due to the mobile bearing the implant is unlikely to fail[31, 32], and because the retained cartilage and bone are strong in the young there disease progression or loosening is unlikely. It was also surprising that the function of UKR in the young was so much better with UKR than TKR. This may be because knee kinematics are virtually normal after UKR whereas it is abnormal after TKR[33, 34].

Revision is the generally accepted definition of failure as this is the data national registries collect. There are a number of problems with this. One, highlighted by the study, is amputation. One patient with a failed TKR had an amputation (Table 5). This would not have been reported to a register so would not be considered a revision despite being a catastrophic outcome; we however considered it a revision. Furthermore, TKR revisions tend to be more major undertakings with worse outcomes than after UKR $[35,36]$, which makes a comparison based on revision alone inappropriate. We have therefore analysed major revision separately. Finally patients are probably more concerned about symptom relief than revision. They would, for example, consider an excellent outcome after a revision to be a success, whereas a register would consider this a failure. Conversely, a patient would consider an implant that did not help their symptoms and was not revised to be a failure whereas a register would consider it a success. To address this we have determined the proportion of patients who are worse post- 
operatively than pre-operatively and have introduced a composite outcome measure in which failure is either no improvement post-operatively or a re-operation/revision.

The main strengths of this study are that the UKR were used for the recommended indications $[3,18,28]$ and were matched to TKR that were done in knees with a disease pattern appropriate for UKR. The numbers were relatively large, the data quality was good and the median follow up was 10 years. As such it probably represents one of the best comparisons that exist between UKR and TKR. As there is nothing similar in the literature, it is difficult to compare with other studies. However an age dependent analysis found higher satisfaction with UKR than TKR in patients under 55 years of age[37]. Studies based on National joint registries have shown much higher revision rates with UKR then TKR and slightly better OKS with UKR $[5-9,38]$. These findings are different from ours probably because many UKR were implanted for early arthritis[39]. This is supported by the recently published results from the Total Or Partial Knee Arthroplasty Trial (TOPKAT), a pragmatic equipoise-based randomised controlled trial of over 500 patients, at 27 UK sites with 68 surgones, which has shown equivalent five-year revision rates with TKR and UKR and supports the results seen in this study [40].

The main weakness is that UKR were implanted by two designer surgeons who did large numbers of UKR, whereas multiple surgeons implanted the TKR. The study may therefore not be generalizable. However the TKR cohort was from a randomised trial that found minimal differences between different designs of knee replacement so probably do reflect the typical results of TKR[17]. There are now multiple published series showing that if surgeons using Oxford UKR adhere to recommended indications they achieve similar ten-year results to the designer surgeons[26, 27, 41-45]. Therefore providing the recommended indications for UKR are used the results are likely to be generalizable. The recommended indications are satisfied in about half of patients requiring knee replacements[2, 3] and the evidence suggests that to 
get good results surgeons should use UKR for at least $20 \%$ and ideally up to $50 \%$ of knee replacements[41, 46, 47]. Furthermore, even if the designer surgeons obtain better results this would affect all age groups equally, and would not account for the trend of better outcomes in younger patients. We cannot be completely certain that all TKR included in the matching would have been appropriate for UKR as we did not have good data on co-morbidities, or the degree of lateral wear and we could not match on these. Further, we don't know if these results are transferable to fixed bearing UKR. Finally, both cohorts were observational and there was no randomisation. The matching process can introduce selection bias, though the sensitivity analysis revealed no deviations from the unmatched data (Table 2, Appendices A and B).

\section{Conclusions.}

We found that when all age groups were combined, UKR provided better functional outcomes with more excellent results and fewer cases in which the post-operative score was less than preoperative. Although there was no significant difference in revision rate UKR did have significantly less major revisions and reoperations/revisions. Also UKR had significantly less failures, defined as no improvement in outcome or revision/reoperation. Similar trends were seen within each age group, with UKR being particularly favourable in young patients. This study therefore suggests, providing the recommended indications are applied, UKR should be used when indicated in all age groups.

Acknowledgements: We would like to acknowledge those involved with the Knee Arthroplasty Trial. In addition, we would like to acknowledge Edward Burn for statistical input, Barbara Marks, and Jo Brown for administrative input, and Cathy Jenkins for her follow up of the UKR patients. 
Funding: This research did not receive any specific grant from funding agencies in the public, commercial, or not-for-profit sectors. 


\section{References}

[1] Ravi B, Croxford R, Reichmann WM, Losina E, Katz JN, Hawker GA. The changing demographics of total joint arthroplasty recipients in the United States and Ontario from 2001 to 2007. Best practice \& research Clinical rheumatology. 2012;26(5):637-47.

[2] Willis-Owen CA, Brust K, Alsop H, Miraldo M, Cobb JP. Unicondylar knee arthroplasty in the UK National Health Service: an analysis of candidacy, outcome and cost efficacy. The Knee. 2009;16(6):473-8.

[3] Hamilton TW, Pandit HG, Lombardi AV, Adams JB, Oosthuizen CR, Clave A, et al. Radiological Decision Aid to determine suitability for medial unicompartmental knee arthroplasty: development and preliminary validation. Bone Joint J. 2016;98-B(10 Supple B):3-10.

[4] 10th Annual Report 2013. National Joint Registry for England, Wales, Northern Ireland and the Isle of Man.

[5] No authors listed. 15th Annual Report 2018. National Joint Registry for England, Wales, Northern Ireland and the Isle of Man. .

[6] No authors listed. Swedish Knee Arthoplasty Register. Annual Report 2018. Lund University, Sweden.

[7] No authors listed. Australian Orthopaedic Association National Joint Replacement Registry. 2018 Annual Report: Hip, Knee \& Shoulder Arthroplasty. Australian Orthopaedic Association. .

[8] No authors listed. The New Zealand Joint Registry, Nineteen Year Report. New Zealand Orthopaedic Association. 2018.

[9] Liddle AD, Pandit H, Judge A, Murray DW. Patient-reported outcomes after total and unicompartmental knee arthroplasty: a study of 14,076 matched patients from the National Joint Registry for England and Wales. Bone Joint J. 2015;97-B(6):793-801.

[10] Von Keudell A, Sodha S, Collins J, Minas T, Fitz W, Gomoll A. Patient satisfaction after primary total and unicompartmental knee arthroplasty: an age-dependent analysis. The Knee. 2014;21(1):180-4.

[11] Lombardi AV, Berend KR, Walter CA, Aziz-Jacobo J, Cheney NA. Is recovery faster for mobile-bearing unicompartmental than total knee arthroplasty? Clinical Orthopaedics and Related Research®. 2009;467(6):1450-7.

[12] Duchman KR, Gao Y, Pugely AJ, Martin CT, Callaghan JJ. Differences in short-term complications between unicompartmental and total knee arthroplasty: a propensity score matched analysis. JBJS. 2014;96(16):1387-94.

[13] Liddle AD, Judge A, Pandit H, Murray DW. Adverse outcomes after total and unicompartmental knee replacement in 101,330 matched patients: a study of data from the National Joint Registry for England and Wales. Lancet. 2014;384(9952):1437-45.

[14] Hunt LP, Ben-Shlomo Y, Clark EM, Dieppe P, Judge A, MacGregor AJ, et al. 45-day mortality after 467779 knee replacements for osteoarthritis from the National Joint Registry for England and Wales: an observational study. The Lancet. 2014;384(9952):1429-36.

[15] Morris MJ, Molli RG, Berend KR, Lombardi Jr AV. Mortality and perioperative complications after unicompartmental knee arthroplasty. The Knee. 2013;20(3):218-20.

[16] Brown NM, Sheth NP, Davis K, Berend ME, Lombardi AV, Berend KR, et al. Total knee arthroplasty has higher postoperative morbidity than unicompartmental knee arthroplasty: a multicenter analysis. The Journal of arthroplasty. 2012;27(8):86-90.

[17] Murray DW, MacLennan GS, Breeman S, Dakin HA, Johnston L, Campbell MK, et al. A randomised controlled trial of the clinical effectiveness and cost-effectiveness of different knee prostheses: the Knee Arthroplasty Trial (KAT). Health technology assessment (Winchester, England). 2014;18(19):1. 
[18] White SH, Ludkowski PF, Goodfellow JW. Anteromedial osteoarthritis of the knee. J Bone Joint Surg Br. 1991;73(4):582-6.

[19] Austin PC. Optimal caliper widths for propensity-score matching when estimating differences in means and differences in proportions in observational studies. Pharmaceutical statistics. 2011;10(2):150-61.

[20] Murray DW, Fitzpatrick R, Rogers K, Pandit H, Beard DJ, Carr AJ, et al. The use of the Oxford hip and knee scores. J Bone Joint Surg Br. 2007;89(8):1010-4.

[21] Beard DJ, Harris K, Dawson J, Doll H, Murray DW, Carr AJ, et al. Meaningful changes for the Oxford hip and knee scores after joint replacement surgery. Journal of clinical epidemiology. 2015;68(1):73-9.

[22] Kiran A, Bottomley N, Biant LC, Javaid MK, Carr AJ, Cooper C, et al. Variations In Good Patient Reported Outcomes After Total Knee Arthroplasty. J Arthroplasty.

2015;30(8):1364-71.

[23] Weston-Simons JS, Pandit H, Jenkins C, Jackson WF, Price AJ, Gill HS, et al. Outcome of combined unicompartmental knee replacement and combined or sequential anterior cruciate ligament reconstruction: a study of 52 cases with mean follow-up of five years. J Bone Joint Surg Br. 2012;94(9):1216-20.

[24] Rodriguez-Mañas L, Fried LP. Frailty in the clinical scenario. The Lancet. 2015;385(9968):e7-e9.

[25] Clegg A, Young J, Iliffe S, Rikkert MO, Rockwood K. Frailty in elderly people. The lancet. 2013;381(9868):752-62.

[26] Yoshida K, Tada M, Yoshida H, Takei S, Fukuoka S, Nakamura H. Oxford phase 3 unicompartmental knee arthroplasty in Japan--clinical results in greater than one thousand cases over ten years. J Arthroplasty. 2013;28(9 Suppl):168-71.

[27] Lisowski LA, Meijer LI, van den Bekerom MP, Pilot P, Lisowski AE. Ten- to 15-year results of the Oxford Phase III mobile unicompartmental knee arthroplasty: a prospective study from a non-designer group. Bone Joint J. 2016;98 B(10 Supple B):41-7.

[28] Hamilton TW, Pandit HG, Jenkins C, Mellon SJ, Dodd CAF, Murray DW. Evidence-

Based Indications for Mobile-Bearing Unicompartmental Knee Arthroplasty in a Consecutive Cohort of Thousand Knees. J Arthroplasty. 2017;32(6):1779-85.

[29] Knifsund J, Hatakka J, Keemu H, Mäkelä K, Koivisto M, Niinimäki T.

Unicompartmental knee arthroplasties are performed on the patients with radiologically too mild osteoarthritis. Scandinavian Journal of Surgery. 2017;106(4):338-41.

[30] Niinimäki TT, Murray DW, Partanen J, Pajala A, Leppilahti JI. Unicompartmental knee arthroplasties implanted for osteoarthritis with partial loss of joint space have high reoperation rates. The Knee. 2011;18(6):432-5.

[31] Simpson DJ, Gray H, D'lima D, Murray D, Gill H. The effect of bearing congruency, thickness and alignment on the stresses in unicompartmental knee replacements. Clinical Biomechanics. 2008;23(9):1148-57.

[32] O'Connor J, Goodfellow J, Dodd C, Murray D. Development and clinical application of meniscal unicompartmental arthroplasty. Proceedings of the Institution of Mechanical Engineers, Part H: Journal of Engineering in Medicine. 2007;221(1):47-59.

[33] Pegg EC, Mancuso F, Alinejad M, van Duren BH, O'Connor JJ, Murray DW, et al. Sagittal kinematics of mobile unicompartmental knee replacement in anterior cruciate ligament deficient knees. Clin Biomech (Bristol, Avon). 2016;31:33-9.

[34] Price AJ, Rees JL, Beard DJ, Gill RH, Dodd CA, Murray DM. Sagittal plane kinematics of a mobile-bearing unicompartmental knee arthroplasty at 10 years: a comparative in vivo fluoroscopic analysis. J Arthroplasty. 2004;19(5):590-7. 
[35] Saldanha K, Keys G, Svard U, White S, Rao C. Revision of Oxford medial unicompartmental knee arthroplasty to total knee arthroplasty-results of a multicentre study. The knee. 2007;14(4):275-9.

[36] Leta TH, Lygre SHL, Skredderstuen A, Hallan G, Gjertsen J-E, Rokne B, et al. Outcomes of unicompartmental knee arthroplasty after aseptic revision to total knee arthroplasty: a comparative study of 768 TKAs and 578 UKAs revised to TKAs from the Norwegian Arthroplasty Register (1994 to 2011). JBJS. 2016;98(6):431-40.

[37] Von Keudell A, Sodha S, Collins J, Minas T, Fitz W, Gomoll AH. Patient satisfaction after primary total and unicompartmental knee arthroplasty: an age-dependent analysis. Knee. 2014;21(1):180-4.

[38] Baker P, Petheram T, Jameson S, Avery P, Reed M, Gregg P, et al. Comparison of patient-reported outcome measures following total and unicondylar knee replacement. The Journal of bone and joint surgery British volume. 2012;94(7):919-27.

[39] Kennedy JA, Palan J, Mellon SJ, Esler C, Dodd CAD, Pandit HG, et al. Most Unicompartmental Knee Replacement revisions could be avoided: A radiographic evaluation of revised Oxford Knees in the National Joint Registry. Knee Surg Sports Traumatol Arthrosc (in press). 2020.

[40] Beard DJ, Davies LJ, Cook JA, MacLennan G, Price A, Kent S, et al. The clinical and cost-effectiveness of total versus partial knee replacement in patients with medial compartment osteoarthritis (TOPKAT): 5-year outcomes of a randomised controlled trial. The Lancet. 2019;394(10200):746-56.

[41] Hamilton TW, Rizkalla JM, Kontochristos L, Marks BE, Mellon SJ, Dodd CAF, et al. The Interaction of Caseload and Usage in Determining Outcomes of Unicompartmental Knee Arthroplasty: A Meta-Analysis. J Arthroplasty. 2017;32(10):3228-37 e2.

[42] Mohammad HR, Strickland L, Hamilton TW, Murray DW. Long-term outcomes of over 8,000 medial Oxford Phase 3 Unicompartmental Knees-a systematic review. Acta orthopaedica. 2018;89(1):101-7.

[43] Price AJ, Svard U. A second decade lifetable survival analysis of the Oxford unicompartmental knee arthroplasty. Clinical Orthopaedics and Related Research ${ }^{\circledR}$. 2011;469(1):174-9.

[44] Emerson R, Alnachoukati O, Barrington J, Ennin K. The results of Oxford unicompartmental knee arthroplasty in the United States: a mean ten-year survival analysis. The bone \& joint journal. 2016;98(10_Supple_B):34-40.

[45] Lim H, Bae J, Song S, Kim S. Oxford phase 3 unicompartmental knee replacement in Korean patients. The Journal of bone and joint surgery British volume. 2012;94(8):1071-6. [46] Liddle AD, Judge A, Pandit H, Murray DW. Determinants of revision and functional outcome following unicompartmental knee replacement. Osteoarthritis Cartilage.

2014;22(9):1241-50.

[47] Murray D, Parkinson R. Usage of unicompartmental knee arthroplasty. Bone Joint J. 2018;100(4):432-5. 


\section{Figure Legends}

Figure 1: Study flow diagram

Figure 2: Median Oxford Knee Score and interquartile range at ten years by age group and prosthesis.

Figure 3: Comparison of revisions by age group, prosthesis type and extent of revision required. Star $(*)$ indicates significant difference $(\mathrm{p}<0.05)$. Line represents $95 \%$ confidence interval. Major revision defined as any operation undertaking more complex than a single stage primary TKR or amputation. NB: As matching was generated within age strata, estimates can't compare between age groups, but rather only between prostheses within each age group.

Figure 4: Comparison of incidence rate difference by age group. Rate is per 100 patient years. Point estimate and 95\% confidence interval provided. OKS Oxford Knee Score, Major Revision defined as any operation with greater than a single stage primary TKR or amputation. 


\begin{tabular}{|l|l|l|l|l|l|l|l|}
\hline Table 1: Characteristics of unmatched and matched cohorts \\
\hline & Unmatched & & & & Matched & & \\
\hline$<60$ & TKR & UKR & SMD & TKR & UKR & SMD \\
\hline Number & 122 & 165 & NA & 83 & 107 & NA \\
\hline Mean Age (SD) & $55.8(5)$ & $54(5)$ & -0.34 & $55.2(4)$ & $55.3(3)$ & 0.01 \\
\hline Mean Weight (SD) & $87.2(17)$ & $88.2(16)$ & 0.06 & $85.6(18)$ & $87.3(18)$ & 0.09 \\
\hline N female (\%) & $53(43 \%)$ & $84(51 \%)$ & 0.15 & $56(46 \%)$ & $70(43 \%)$ & -0.06 \\
\hline Mean preop OKS (SD) & $16.4(9)$ & $24.1(9)$ & 0.82 & $18.5(7)$ & $18.6(7)$ & 0.01 \\
\hline Mean follow up (SD) & $9.3(3)$ & $9.6(4)$ & 0.1 & $9.7(3)$ & $9.6(4)$ & -0.02 \\
\hline & & & & & & \\
\hline 60-<75 & TKR & UKR & SMD & TKR & UKR & SMD \\
\hline Number & 802 & 365 & NA & 631 & 306 & NA \\
\hline Mean Age (SD) & $68.3(4)$ & $67.5(4)$ & -0.18 & $67.9(4)$ & $67.9(4)$ & 0.00 \\
\hline Mean Weight (SD) & $84.4(16)$ & $82.7(14)$ & -0.1 & $82.8(15)$ & $83.2(16)$ & 0.02 \\
\hline N female (\%) & $384(48 \%)$ & $200(55 \%)$ & 0.14 & $326(52 \%)$ & $164(54 \%)$ & 0.04 \\
\hline Mean Preop OKS (SD) & $18.6(7)$ & $24.3(9)$ & 0.67 & $22.1(7)$ & $22.2(8)$ & 0.01 \\
\hline Mean Follow up (SD) & $9.4(3)$ & $9.6(3)$ & 0.05 & $9.7(3)$ & $9.7(3)$ & 0.00 \\
\hline & & & & & & \\
\hline $75+$ & TKR & UKR & SMD & TKR & UKR & SMD \\
\hline Number & 465 & 148 & NA & 243 & 115 & NA \\
\hline Mean Age (SD) & $79.4(3)$ & $79.3(3)$ & -0.06 & $79.2(3)$ & $79.4(3)$ & 0.06 \\
\hline Mean Weight (SD) & $75.7(15)$ & $71.6(13)$ & -0.32 & $72.9(14)$ & $72.6(13)$ & -0.02 \\
\hline N female (\%) & $197(42 \%)$ & $67(45 \%)$ & 0.06 & $107(44 \%)$ & $52(45 \%)$ & 0.03 \\
\hline Mean Preop OKS (SD) & $18.5(7)$ & $26.2(8)$ & 0.89 & $23.8(7)$ & $24(8)$ & 0.02 \\
\hline Mean Follow up (SD) & $7.5(3)$ & $8.2(2)$ & 0.25 & $8.4(3)$ & $8.2(3)$ & -0.06 \\
\hline $\begin{array}{l}\text { SD standard deviation, OKS Oxford Knee Score, Preop Pre-operative, N number, } \\
\text { TKR total knee replacement, UKR unicompartmental knee replacement, }\end{array}$ \\
SMD standardized mean difference, NA not applicable & & & \\
\hline
\end{tabular}




\begin{tabular}{|l|l|l|l|l|l|l|}
\hline Table 2 Revision outcomes in unmatched data \\
\hline $\begin{array}{l}\text { Age } \\
\text { group }\end{array}$ & $\begin{array}{l}\text { N revisions (\% of } \\
\text { cohort) }\end{array}$ & $\begin{array}{l}\text { Component time incidence rate (95\% confidence } \\
\text { interval) }\end{array}$ & $\begin{array}{l}\text { Ten year Kaplan-Meier survival (95\% confidence } \\
\text { interval) }\end{array}$ & \\
\hline & TKR & UKR & TKR & UKR & TKR & UKR \\
\hline$<60$ & $18(14 \%)$ & $12(5 \%)$ & $1.52(0.9-2.4)$ & $0.53(0.3-0.9)$ & $85.5 \%(80-92)$ & $95.7 \%(93-98)$ \\
\hline $60-75$ & $34(4 \%)$ & $30(5 \%)$ & $0.43(0.3-0.6)$ & $0.59(0.4-0.8)$ & $95.9 \%(94-97)$ & $93.8 \%(91-96)$ \\
\hline $75+$ & $16(3 \%)$ & $10(5 \%)$ & $0.44(0.2-0.7)$ & $0.60(0.3-1.1)$ & $95.9 \%(94-98)$ & $93.0 \%(88-98)$ \\
\hline
\end{tabular}




\begin{tabular}{|c|c|c|c|c|c|c|c|c|c|}
\hline \multirow[t]{2}{*}{ Age } & \multicolumn{3}{|l|}{$<60$} & \multicolumn{3}{|l|}{$60-<75$} & \multicolumn{3}{|l|}{$75+$} \\
\hline & TKR & UKR & $P$ value & TKR & UKR & $P$ value & TKR & UKR & $P$ value \\
\hline \multicolumn{10}{|l|}{ Year 5 OKS } \\
\hline Mean (SD) & $34.8(10)$ & $39.8(10)$ & $<0.01$ & $36.2(10)$ & $41.2(7)$ & $<0.001$ & $35.4(10)$ & $39.6(8)$ & $<0.001$ \\
\hline $\begin{array}{l}\text { Median } \\
(\mathrm{IQR})\end{array}$ & $36(29-42)$ & $44(36-47)$ & $<0.001$ & $39(30-44)$ & $43(39-46)$ & $<0.001$ & $38(28-44)$ & $42(35-46)$ & $<0.01$ \\
\hline POPC (IQR) & $\begin{array}{c}52.9 \%(39- \\
79)\end{array}$ & $\begin{array}{c}83.9 \%(62- \\
94)\end{array}$ & $<0.001$ & $\begin{array}{c}65.8 \%(37- \\
83)\end{array}$ & $\begin{array}{c}81.8 \%(64- \\
92)\end{array}$ & $<0.001$ & $\begin{array}{c}59.2 \%(27- \\
86)\end{array}$ & $\begin{array}{c}75.6 \%(50- \\
91)\end{array}$ & $<0.01$ \\
\hline $\begin{array}{l}\text { N Excellent } \\
\text { OKS }(\%)\end{array}$ & $19(30 \%)$ & $51(63 \%)$ & $<0.001$ & $199(38 \%)$ & $159(65 \%)$ & $<0.001$ & $70(40 \%)$ & $44(54 \%)$ & 0.04 \\
\hline \multicolumn{10}{|l|}{ Year 10 OKS } \\
\hline Mean (SD) & $32.4(11)$ & $39.6(10)$ & $<0.001$ & $34.8(10)$ & $39.0(9)$ & $<0.001$ & $32.9(11)$ & $35.5(11)$ & 0.25 \\
\hline $\begin{array}{l}\text { Median } \\
(\mathrm{IQR})\end{array}$ & $33(26-41)$ & $45(34-47)$ & $<0.001$ & $37(28-43)$ & $42(35-46)$ & $<0.001$ & $36(25-43)$ & $38(30-44)$ & 0.24 \\
\hline POPC (IQR) & $\begin{array}{c}51.5 \%(27- \\
75)\end{array}$ & $\begin{array}{c}88.0 \%(62- \\
96)\end{array}$ & $<0.001$ & $\begin{array}{c}59.5 \%(29- \\
81)\end{array}$ & $\begin{array}{c}75.4 \%(52- \\
91)\end{array}$ & $<0.001$ & $\begin{array}{c}46.2 \%(16- \\
77)\end{array}$ & $\begin{array}{c}61.4 \%(28- \\
86)\end{array}$ & 0.12 \\
\hline $\begin{array}{l}\text { N Excellent } \\
\text { OKS }(\%)\end{array}$ & $12(21 \%)$ & $37(63 \%)$ & $<0.001$ & $127(33 \%)$ & $79(52 \%)$ & $<0.001$ & $21(27 \%)$ & $11(34 \%)$ & 0.46 \\
\hline
\end{tabular}




\begin{tabular}{|c|c|c|c|c|c|c|c|}
\hline \multirow{2}{*}{$\begin{array}{l}\text { Table } 2 \\
\text { Age } \\
\text { group }\end{array}$} & \multicolumn{2}{|c|}{$\begin{array}{l}\mathrm{N} \text { revisions (\% of } \\
\text { cohort) }\end{array}$} & \multicolumn{2}{|c|}{$\begin{array}{l}\text { Component time incidence } \\
\text { rate }(95 \% \text { confidence } \\
\text { interval })\end{array}$} & \multicolumn{2}{|c|}{$\begin{array}{l}\text { Ten year Kaplan-Meier } \\
\text { survival }(95 \% \text { confidence } \\
\text { interval })\end{array}$} & \multirow[b]{2}{*}{$\begin{array}{l}\mathrm{P} \\
\text { value }\end{array}$} \\
\hline & TKR & UKR & TKR & UKR & TKR & UKR & \\
\hline \multicolumn{8}{|c|}{ Reoperation (any knee procedure requiring general or regional anaesthetic) } \\
\hline$<60$ & $\begin{array}{c}15 \\
(18 \%)\end{array}$ & $\begin{array}{c}13 \\
(12 \%)\end{array}$ & $\begin{array}{c}2.02(1.1- \\
3.3)\end{array}$ & $\begin{array}{c}1.30(0.7- \\
2.2)\end{array}$ & $\begin{array}{c}81.7(74- \\
91)\end{array}$ & 89.5 (84-96) & 0.25 \\
\hline $60-75$ & $\begin{array}{c}58 \\
(9 \%)\end{array}$ & $\begin{array}{c}21 \\
(7 \%)\end{array}$ & $\begin{array}{c}1.00(0.8- \\
1.3)\end{array}$ & $\begin{array}{c}0.72(0.4- \\
1.1)\end{array}$ & $\begin{array}{l}90.6(88- \\
93)\end{array}$ & $92.5(89-96)$ & 0.19 \\
\hline $75+$ & $\begin{array}{c}13 \\
(5 \%) \\
\end{array}$ & $9(8 \%)$ & $\begin{array}{c}0.67(0.4- \\
1.1) \\
\end{array}$ & $\begin{array}{c}0.98(0.4- \\
1.9) \\
\end{array}$ & $\begin{array}{l}93.9(91- \\
97) \\
\end{array}$ & 88.6 (81-97) & 0.36 \\
\hline \multicolumn{8}{|c|}{$\begin{array}{l}\text { Revision (subset requiring implant addition, exchange, removal, amputation or ORIF of periprosthetic } \\
\text { fracture) }\end{array}$} \\
\hline$<60$ & $\begin{array}{c}9 \\
(11 \%)\end{array}$ & $8(7 \%)$ & $\begin{array}{l}1.12(0.5- \\
2.1)\end{array}$ & $\begin{array}{c}0.77(0.3- \\
1.5)\end{array}$ & $\begin{array}{l}88.9(82- \\
96)\end{array}$ & $92.7(88-98)$ & 0.54 \\
\hline $60-75$ & $\begin{array}{c}29 \\
(5 \%)\end{array}$ & $\begin{array}{c}14 \\
(5 \%)\end{array}$ & $\begin{array}{l}0.48(0.3- \\
0.7)\end{array}$ & $\begin{array}{c}0.47(0.3- \\
0.8)\end{array}$ & $\begin{array}{l}95.3(94- \\
97)\end{array}$ & $94.8(92-98)$ & 0.95 \\
\hline $75+$ & $\begin{array}{c}11 \\
(5 \%)\end{array}$ & $7(6 \%)$ & $\begin{array}{l}0.56(0.3- \\
1.0)\end{array}$ & $\begin{array}{l}0.74(0.3- \\
1.5)\end{array}$ & $\begin{array}{l}94.7(92- \\
98)\end{array}$ & $90.4(83-98)$ & 0.52 \\
\hline \multicolumn{8}{|c|}{ Major revision (subset requiring greater than a single stage primary TKR, or amputation) } \\
\hline$<60$ & $7(8 \%)$ & $0(0 \%)$ & $\begin{array}{c}0.87(0.3- \\
1.8)\end{array}$ & $\begin{array}{c}0.00(0.0- \\
0.4)\end{array}$ & $\begin{array}{c}91.4(85- \\
98)\end{array}$ & $\begin{array}{c}100.0(100- \\
100)\end{array}$ & 0.003 \\
\hline $60-75$ & $\begin{array}{c}24 \\
(4 \%) \\
\end{array}$ & $1(0 \%)$ & $\begin{array}{c}0.40(0.3- \\
0.6) \\
\end{array}$ & $\begin{array}{c}0.03(0.0- \\
0.2) \\
\end{array}$ & $\begin{array}{l}96.1(95- \\
98) \\
\end{array}$ & $99.4(98-100)$ & 0.004 \\
\hline $75+$ & $8(3 \%)$ & $0(0 \%)$ & $\begin{array}{c}0.41(0.2- \\
0.8)\end{array}$ & $\begin{array}{c}0.00(0.0- \\
0.4)\end{array}$ & $\begin{array}{c}96.1(93- \\
99) \\
\end{array}$ & $\begin{array}{c}100.0(100- \\
100)\end{array}$ & 0.05 \\
\hline
\end{tabular}




\begin{tabular}{|c|c|c|}
\hline $\begin{array}{l}\text { Age } \\
\text { group }\end{array}$ & TKR & UKR \\
\hline$<60$ & $\begin{array}{l}\text { Infection (two stage) } \times 3 \\
\text { Loosening (revision) } \mathrm{x} 2 \\
\text { Pain (patellar resurfacing) x2 } \\
\text { Dislocation (unspecified revision) } \\
\text { Pain (unspecified revision) }\end{array}$ & $\begin{array}{l}\text { Disease progression (primary TKR) x3 } \\
\text { Pain (primary TKR) } \mathrm{x} 2 \\
\text { Disease progression (lateral UKR) } \\
\text { Dislocated bearing (bearing exchange and } \\
\text { femoral component revision) }\end{array}$ \\
\hline $60-75$ & $\begin{array}{l}\text { Loosening x } 12 \\
\text { Infection (two stage) x } 4 \\
\text { Bearing dislocation (unspecified } \\
\text { revision) } \\
\text { Pain (patellar resurfacing) } \\
\text { Instability (unspecified revision) } \\
\text { Pain (unspecified) } \\
\text { Malalignment (unspecified revision) } \\
\text { Stiffness (unspecified revision) } \\
\text { Patella revision (failed patella resurfacing } \\
\text { x 1, loose patella x 1) }\end{array}$ & $\begin{array}{l}\text { Disease progression (primary TKR) x } 4 \\
\text { Disease progression (lateral UKR) x } 3 \\
\text { Bearing exchange (dislocation) x } 2 \\
\text { Pain (primary TKR) x } 2 \\
\text { Instability (hinged TKR) } \\
\text { Unknown (primary TKR) }\end{array}$ \\
\hline $75+$ & $\begin{array}{l}\text { Infection (two stage) } \times 3 \\
\text { Loosening } \times 3 \\
\text { Pain (patellar resurfacing) x } 3 \\
\text { Unspecified indication (Above knee } \\
\text { amputation) }\end{array}$ & $\begin{array}{l}\text { Disease progression (primary TKR) x } 3 \\
\text { Disease progression (lateral UKR) x } 2 \\
\text { Tibial loosening (primary TKR) } \\
\text { Pain (primary TKR) }\end{array}$ \\
\hline
\end{tabular}




\begin{tabular}{|c|c|c|}
\hline $\begin{array}{l}\text { Age } \\
\text { group }\end{array}$ & TKR & UKR \\
\hline$<60$ & $\begin{array}{l}\text { Washout (wound dehiscence) } \times 2 \\
\text { Washout (infection) } 22 \\
\text { MUA (Stiffness) } \times 3\end{array}$ & $\begin{array}{l}\text { Arthroscopy (pain) } \mathrm{x} 2 \\
\text { Arthroscopy and washout (Pain - performed } \\
\text { elsewhere) } \\
\text { Arthroscopy, and debridement (unspecified) x } 2 \\
\text { MUA (Stiffness) }\end{array}$ \\
\hline $60-75$ & $\begin{array}{l}\text { Arthroscopy (pain) x } \\
\text { Arthroscopy and biopsy (suspected infection) } \\
\text { x2 } \\
\text { Change of poly (dislocation x 1, infection x 1, } \\
\text { prosthetic complication x 1) } \\
\text { Debridement (infection) x } 5 \\
\text { Debridement, exploration and washout } \\
\text { (infection) } 1 \\
\text { EUA (stiffness x 1) } \\
\text { EUA and arthroscopy (diagnostic op) x } 1 \\
\text { Excision of bone fragment x } 1 \\
\text { Excision of lateral patella x } 1 \\
\text { MUA (stiffness) x } 17 \\
\text { Patella resurfacing (pain) x } 1 \\
\text { Washout (infection) } \times 4\end{array}$ & $\begin{array}{l}\text { Arthroscopy } \mathrm{x} 5 \\
\text { Arthroscopy and washout x } 1 \\
\text { MUA x } 7\end{array}$ \\
\hline $75+$ & $\begin{array}{l}\text { Washout (infection) } \times 2 \\
\text { Washout and debridement (infection) } \\
\text { MUA (stiffness) } \times 2 \\
\text { Debridement (infection) }\end{array}$ & MUA (Stiffness) x2 \\
\hline
\end{tabular}


Appendix

\begin{tabular}{|c|c|c|c|c|c|c|c|c|c|}
\hline & $<60$ & & & $60-<75$ & & & $75+$ & & \\
\hline & TKR & UKR & $P$ value & TKR & UKR & $\mathrm{P}$ value & TKR & UKR & $\begin{array}{l}\mathrm{P} \\
\text { value }\end{array}$ \\
\hline Year $5 \mathrm{OK}$ & & & & & & & & & \\
\hline $\begin{array}{l}\text { Mean } \\
\text { (SD) }\end{array}$ & $\begin{array}{l}32.9 \\
(11) \\
\end{array}$ & $\begin{array}{c}40.7 \\
(8) \\
\end{array}$ & $<0.001$ & $\begin{array}{l}35.1 \\
(10) \\
\end{array}$ & $\begin{array}{c}41.8 \\
(7) \\
\end{array}$ & $<0.001$ & $\begin{array}{l}33.8 \\
(11) \\
\end{array}$ & $\begin{array}{c}40.4 \\
(8) \\
\end{array}$ & $<0.001$ \\
\hline $\begin{array}{l}\text { Median } \\
\text { (IQR) }\end{array}$ & $\begin{array}{c}35 \\
(25-42)\end{array}$ & $\begin{array}{c}44 \\
(37-47)\end{array}$ & $<0.001$ & $\begin{array}{c}38 \\
(28-43)\end{array}$ & $\begin{array}{c}44 \\
(40-47)\end{array}$ & $<0.001$ & $\begin{array}{l}36 \\
(26- \\
43)\end{array}$ & $\begin{array}{c}44 \\
(37- \\
46)\end{array}$ & $<0.001$ \\
\hline POPC & 51.3 & 69.4 & $<0.001$ & 55.5 & 71.6 & $<0.001$ & 49.9 & 62.4 & $<0.001$ \\
\hline $\begin{array}{l}\mathrm{N} \\
\text { Excellent } \\
\text { OKS (\%) }\end{array}$ & $\begin{array}{c}27 \\
(27)\end{array}$ & $\begin{array}{l}113 \\
(63)\end{array}$ & $<0.001$ & $\begin{array}{l}213 \\
(33)\end{array}$ & $\begin{array}{l}282 \\
(68)\end{array}$ & $<0.001$ & $\begin{array}{c}87 \\
(32)\end{array}$ & $\begin{array}{c}88 \\
(63)\end{array}$ & $<0.001$ \\
\hline Year $10 \mathrm{O}$ & & & & & & & & & \\
\hline $\begin{array}{l}\text { Mean } \\
\text { (SD) }\end{array}$ & $31.0(12)$ & $40.9(9)$ & $<0.001$ & $33.8(10)$ & $\begin{array}{c}39.8 \\
(9)\end{array}$ & $<0.001$ & $\begin{array}{l}31.6 \\
(13)\end{array}$ & $\begin{array}{c}37.1 \\
(9)\end{array}$ & 0.002 \\
\hline $\begin{array}{l}\text { Median } \\
\text { (IQR) }\end{array}$ & $\begin{array}{c}32 \\
(21-42)\end{array}$ & $\begin{array}{c}45 \\
(37-47)\end{array}$ & $<0.001$ & $\begin{array}{c}35 \\
(27-43)\end{array}$ & $\begin{array}{c}42 \\
(36-47)\end{array}$ & $<0.001$ & $\begin{array}{l}36 \\
(22- \\
44) \\
\end{array}$ & $\begin{array}{c}38 \\
(31- \\
44) \\
\end{array}$ & 0.007 \\
\hline POPC & 44.1 & 70.1 & $<0.001$ & 51.2 & 56.4 & $<0.001$ & 41.5 & 58.3 & 0.05 \\
\hline $\begin{array}{l}\mathrm{N} \\
\text { Excellent } \\
\text { OKS }(\%)\end{array}$ & $\begin{array}{c}22 \\
(26)\end{array}$ & $76(66)$ & $<0.001$ & $139(30)$ & $141(54)$ & $<0.001$ & $\begin{array}{c}33 \\
(29)\end{array}$ & $\begin{array}{c}25 \\
(39)\end{array}$ & 0.16 \\
\hline
\end{tabular}

\begin{tabular}{|c|c|c|}
\hline Table B & \multicolumn{2}{|c|}{ Revision indication and outcome by age group and prosthesis unmatched } \\
\hline $\begin{array}{l}\text { Age } \\
\text { group }\end{array}$ & TKR & UKR \\
\hline$<60$ & $\begin{array}{l}\text { Patellar dislocation } \\
\text { Two stage revision (infection) x } 6 \\
\text { Loosening x } 4 \\
\text { Patellar resurfacing x } 5 \\
\text { Pain (unspecified) x } 2\end{array}$ & $\begin{array}{l}\text { Primary TKR (ACL injury) } \\
\text { Bearing exchange (dislocation x } 3 \text { ) } \\
\text { Bearing exchange and femoral component } \\
\text { revision (bearing dislocation) } \\
\text { Disease progression (primary TKR) x } 4 \\
\text { Disease progression (lateral UKR) x } 1 \\
\text { Two stage primary TKR x } 1 \\
\text { Tibial component revision (malposition) } x \\
1\end{array}$ \\
\hline $60-75$ & $\begin{array}{l}\text { Dislocation } \\
\text { Two stage revision (infection) x } 7 \\
\text { Instability x } 3 \\
\text { Loosening x } 14 \\
\text { Malalignment } \\
\text { Patella resurfacing x6 } \\
\text { Unspecified (pain) x } 1 \\
\text { Unspecified x } 1\end{array}$ & $\begin{array}{l}\text { Primary TKR (loosening) } \\
\text { Primary TKR (AVN Lateral femoral } \\
\text { condyle) } \\
\text { Bearing exchange (dislocation) x } 2 \\
\text { Lateral UKR (disease progression) x } 7 \\
\text { Primary TKR (disease progression) x } 9 \\
\text { Two stage primary TKR (infection) x } 1 \\
\text { Two stage TKR with stemmed tibia } \\
\text { (infection) } 1 \\
\text { Hinged TKR (instability) x } 1 \\
\text { Primary TKR (unexplained pain) x } 6\end{array}$ \\
\hline
\end{tabular}




\begin{tabular}{|c|c|c|}
\hline & & $\begin{array}{llll}\begin{array}{l}\text { Primary } \\
\text { overseas) }\end{array} & \text { TKR } & \text { (Unknown } & \text {-revised } \\
\end{array}$ \\
\hline $75+$ & $\begin{array}{l}\text { Two stage revision (infection) } \times 4 \\
\text { Loosening } \times 7 \\
\text { Patellar resurfacing } \times 5\end{array}$ & $\begin{array}{l}\text { Loosening (primary TKR) x } 1 \\
\text { Bearing dislocation (exchange) x } 1 \\
\text { Disease progression (primary TKR) x } 3 \\
\text { Disease progression (lateral UKR) x } 3 \\
\text { Infection (two stage primary TKR) x } 1 \\
\text { Infection (two-stage TKR with stemmed } \\
\text { tibia) } \\
\text { Pain (primary TKR) x } 1\end{array}$ \\
\hline
\end{tabular}

